\title{
Erratum to: Does being an Olympic city help improve recreational resources? Examining the quality of physical activity resources in a low-income neighborhood of Rio de Janeiro
}

\author{
Fabiana R. de Sousa-Mast • Arianne C. Reis • Marcelo C. Vieira • \\ Sandro Sperandei · Luilma A. Gurgel · Uwe Pühse
}

Published online: 14 September 2016

(c) Swiss School of Public Health (SSPH+) 2016

\section{Erratum to: Int J Public Health \\ DOI 10.1007/s00038-016-0827-7}

Figure 2 of the paper "Does being an Olympic city help improve recreational resources? Examining the quality of physical activity resources in a low-income neighborhood of Rio de Janeiro (DOI: 10.1007/s00038-016-0827-7)" presents an error in the label for the legend, and what was designated as group 3 should have been group 1, and viceversa. The figure in the Erratum (below) is the corrected version of the figure.

The online version of the original article can be found under doi:10.1007/s00038-016-0827-7.

F. R. de Sousa-Mast $(\bowtie) \cdot$ U. Pühse

Department of Sport, Exercise and Health, University of Basel, Birsstrasse 320, 4052 Basel, Switzerland

e-mail: fabiana.rodrigues@unibas.ch

A. C. Reis

School of Science and Health, Western Sydney University,

Campbelltown Campus, Locked Bag 1797, Penrith, NSW 2751,

Australia

M. C. Vieira

Center for Cardiology and Exercise, State Institute of Cardiology Aloysio de Castro, Rua Davi Campista, 326, Humaitá, Rio de

Janeiro-RJ CEP 22261-010, Brazil

\section{S. Sperandei}

Institute of Scientific and Technological Communication and Information in Health, Oswaldo Cruz Foundation (FIOCRUZ), Av. Brasil, 4.365, Pavilhão Haity Moussatché, Manguinhos, Rio de Janeiro-RJ CEP 21040-900, Brazil

L. A. Gurgel

State University of Ceará, Av. Dr. Silas Munguba, 1700, Campus do Itaperi, Fortaleza-CE CEP 60714-903, Brazil 


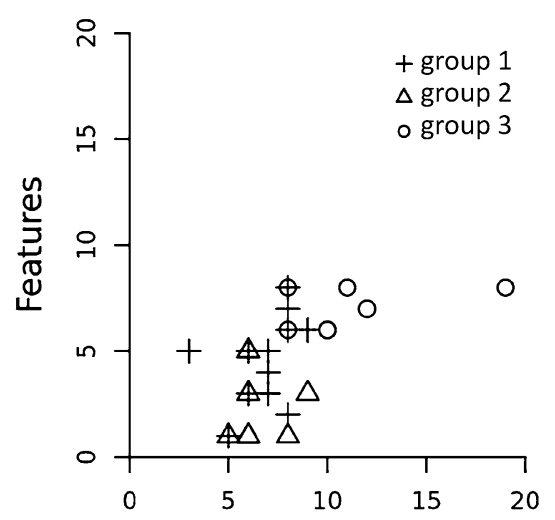

Amenities

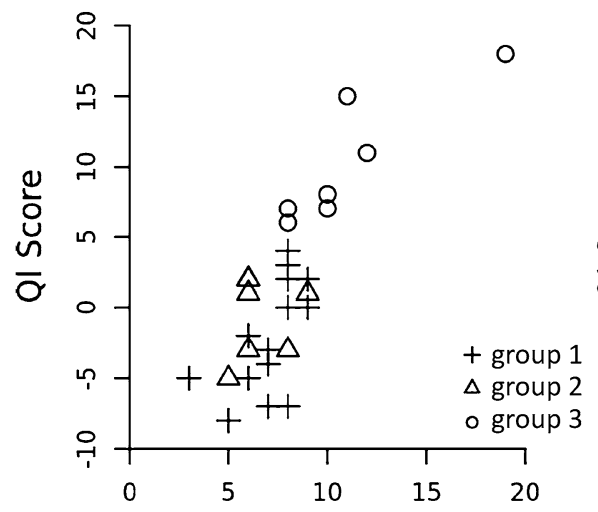

Amenities

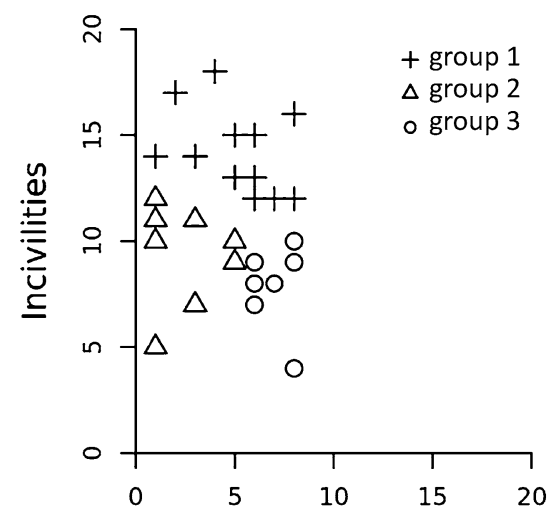

Features

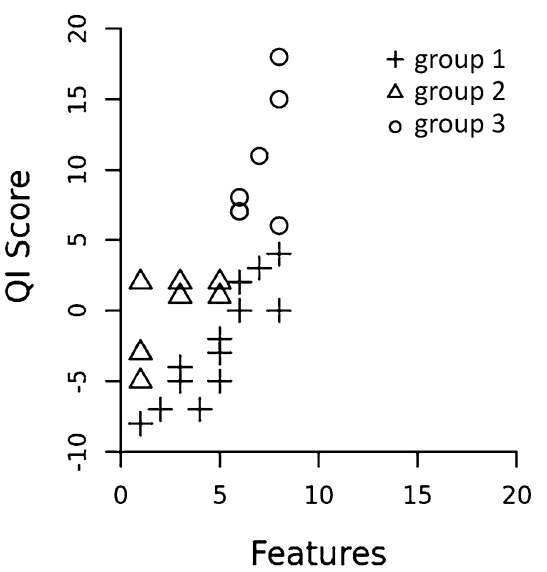

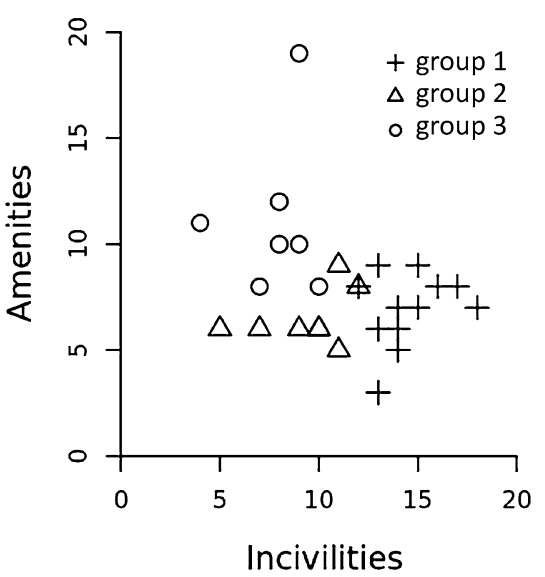

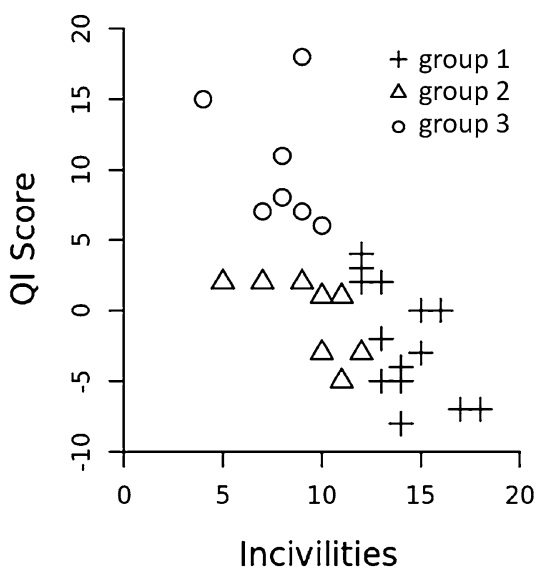

Fig. 2 Distribution of praças according to the cluster, features, amenities, incivilities, and quality indicator (Cidade de Deus, Rio de Janeiro, Brazil, April-July, 2012) 